\title{
Comparison of Nutritional Status with Clinical Status, Laboratory Results and NRS-2002 Score in Patients Requiring Nutritional Support
}

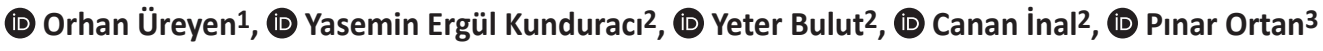 \\ 1 University of Health Sciences, Izmir Bozyaka Training and Research Hospital, Department of General Surgery, Nutrition Support Unit, Izmir, Turkey \\ 2 University of Health Sciences, Izmir Bozyaka Training and Research Hospital, Nutrition Support Unit, Izmir, Turkey \\ 3University of Health Sciences, İzmir Bozyaka Training and Research Hospital, Department of Neurology, Izmir, Turkey
}

\section{Abstract}

Objective: It is known that treatment is more difficult, and morbidity and mortality increases in cases where nutritional support is required. Nutritional risk screening-2002 (NRS) score and the presence of malnutrition were investigated in patients who were consulted to our nutritional support team and the relationship between this scoring and clinical course was investigated. 2002 and the presence of malnutrition were investigated in patients who were consulted to our nutritional support team and the relationship between this scoring and clinical course was investigated.

Methods: The patients who were consulted to nutrition support team between January 2013 and June 2016 were included in this retrospective study. Patients with and without malnutrition according to NRS-2002 were compared in terms of age, gender, primary disease, body mass index (BMI), calorie need, albumin, prealbumin, C-reactive protein and the length of hospital stay.

Results: A total of 450 cases were included in the study. There was a significant difference in terms of age, BMI, albumin value and mortality among cases with and without malnutrition. Mortality was not observed in the cases without malnutrition, and one out of five cases with malnutrition was found to die. According to the correlation analysis, it was observed that malnutrition score increased as age increased, and that malnutrition score decreased as BMI, calorie need and albumin values increased. There was no difference between two groups in terms of gender, diagnosis, prealbumin, C-reactive protein and length of hospital stay.

Conclusion: Our study emphasized the importance of absolute review of body mass index, albumin and C-reactive protein levels in order to evaluate malnutrition more effectively in patients with malnutrition according to NRS-2002. We think that it is important to monitor the patients closely by establishing nutritional support units in hospitals, especially in the neurology and oncology clinics, since the detection of malnutrition and nutritional support affects the clinical course.

Keywords: Albumin, nutrition, malnutrition

\section{INTRODUCTION}

Malnutrition is quite high (20-40\%) in hospitalized patients. Its prevalence depends on the assessment of underlying nutritional difficulties and clinical evaluation parameters $(1,2)$. It is known that treatment is more difficult and morbidity-mortality increases in cases requiring nutritional support (3, 4). Although various assessment methods and indicators (biochemical tests and anthropometric indices) are currently used in the

Presented: This study was presented in the $10^{\text {th }}$ Congress of Clinical Enteral Parenteral Nutrition (KEPAN)

Received: 10.06 .2017 (29 March-2 April 2017, Antalya).

Address for Correspondence: Orhan Üreyen, University of Health Sciences, İzmir Bozyaka Training and Research Hospital, Department of General Surgery, Nutrition Support Unit, İzmir, Turkey E-posta: drureyen@yahoo.com ORCID ID: orcid.org/0000-0002-7820-9088

Cite this article as: Üreyen O, Ergül Kunduracı Y, Bulut Y, Inal C, Ortan P. Comparison of Nutritional Status with Clinical Status, Laboratory Results and NRS-2002 Score in Patients Requiring Nutritional Support. Eur Arch Med Res 2019; 35 (2): 60-5

๑Copyright 2019 by the Health Sciences University, Okmeydanı Training and Research Hospital European Archives of Medical Research published by Galenos Publishing House. 
assessment of nutritional status, there is no scale that is accepted as the gold standard (5). Malnutrition is critically important in hospitalized patients and is associated with poor wound healing, high risk of postoperative infection, decreased efficacy, and prolonged hospital stay (6). Some traditional approaches, such as body mass index (BMI), biochemical test and anthropometric measurements are used in the diagnosis of malnutrition, alone or in combination (5).

Nutritional risk screening-2002 (NRS) is a screening system developed by Kondrup et al. (7). It is suggested that the nutritional status is related to the severity of the disease. This scoring system includes several parameters such as weight loss, BMI and oral intake, presence of additional disease, age and general condition of the patient. It is also a recommended screening test for hospitalized patients by the European Society for Clinical Nutrition and Metabolism. In this screening system, 3 points or more indicate malnutrition. In many studies, NRS was used in the parameters used to determine the other nutritional status and was found to be more useful and more sensitive than the others. Albumin, prealbumin, C-reactive protein (CRP) and BMI are used to determine nutritional status. However, their use alone in determining nutritional status is controversial (8).

\section{Objective}

The presence of malnutrition was investigated by NRS-2002 in patients consulted to our nutrition support team, and the relationship between this scoring and clinical course was investigated. In addition, the relationships between NRS-2002 score of 3-7 and the variables such as age, gender, BMI, primary diagnosis, energy need, hospital stay after nutritional support and the patient's final condition will be investigated.

\section{Hypothesis}

There is relationship between albumin, prealbumin, CRP, age, gender and BMI between patients with and without malnutrition according to NRS.

\section{METHODS}

Our study was approved by the Ethics Committee of İmir Bozyaka Training and Research Hospital, University of Health Sciences (no: 3, dated: 09.08.2016). This study was a retrospective cohort study and included 450 patients who were consulted to our nutritional support unit (NSU) with the diagnosis of malnutrition between January 2013 and June 2016. All subjects were included in the study. Dependent variables were determined as the NRS score and the patient's final status (discharge, transfer, death).
The independent variables were age, gender, primary disease of the patient (such as oncological, neurological, cardiovascular diseases, chronic renal failure, coronary artery diseases), mortality, biochemical parameters (albumin, prealbumin, CRP) which are related or assumed to be related to malnutrition, BMI, daily calorie need and length of hospital stay after nutritional supplementation.

\section{Dependent Variables}

NRS score: the NSU used the table suggested by Kondrup et al., (7) to calculate NRS-2002 score. According to the score, patients having a score $\geq 3$ were classified as malnourished group and patients having a score $<3$ were classified as well-nourished group.

Length of hospitalization: it was evaluated as the time from the consultation date to the final status of the patient.

\section{Independent Variables}

a) Variables related to the clinical situation Age, gender and primary diagnosis: the data were collected from the patient files and nutritional assessment forms. Primary diagnoses were grouped as oncological, neurological, cardiovascular diseases and other.

Mortality status: the patients who died during the hospitalization period were evaluated.

b) Variables related to nutritional status

BMI: BMI is the value calculated by dividing weight $(\mathrm{kg})$ by the square of height in meters [Weight $(\mathrm{kg}) /$ height $\left.\left(\mathrm{m}^{2}\right)\right]$. BMI values were grouped as follows: $<18.5 \mathrm{~kg} / \mathrm{m}^{2}$ as underweight, between $18.5-24.9 \mathrm{~kg} / \mathrm{m}^{2}$ as normal weight, between $25-29.9 \mathrm{~kg} / \mathrm{m}^{2}$ as overweight and $\geq 30$ as obese.

Daily calorie need: It was calculated using Schofield formulas (9) and factors such as presence of infection, ventilation and fever were considered.

c) Biochemical parameters: albumin, prealbumin and CRP values were used in the initial evaluation by the NSU. The values within the three days following the onset of intervention were used for the patients with missing parameters in the initial evaluation. Cases without relevant tests were not included in the statistical analysis. The parameters were grouped as follows:

-Albumin: normal (above 3.5g/dL), low (2.5-3.4 g/dL) and very low (below $2.4 \mathrm{~g} / \mathrm{dL}$ ),

-Prealbumin: normal (above $20 \mathrm{mg} / \mathrm{dL}$ ), low (20-12 mg/dL) and very low (below $11 \mathrm{mg} / \mathrm{dL}$ ), 
-CRP: normal (0-10 mg/L), high (11-50 mg/L) and very high (over $51 \mathrm{mg} / \mathrm{L})$.

\section{Statistical Analysis}

IBM SPSS (Statistical Package for the Social Sciences) version 21.0 program was used for statistical analysis. Numerical variables are summarized with mean, standard deviation, minimum and maximum values. Categorical variables are expressed as numbers and percentages. The normality of numerical variables was examined by Kolmogorov-Smirnov test. Numerical variables were compared between two groups by Student's t-test or Mann-Whitney U test, where appropriate. The difference between three or more independent groups was evaluated by using one-way ANOVA or Kruskal-Wallis test, where appropriate. The relationship between numerical variables was investigated by Pearson or Spearman correlation coefficients. The significance level was taken as $p<0.05$ in all statistical analyzes.

\section{RESULTS}

Regarding genders, $52.4 \%$ of the study group was male and $47.6 \%$ was female. Seventy one point five percent of patients with nutritional support were 65 years or older. Thirty-seven point two percent of the patients had neurological and $30.7 \%$ of the patients had oncological primary diagnoses. According to the BMI levels, 57.4\% were normal. Regarding calorie distributions, it was determined that $48.7 \%$ of the calorie need was in the 1501 1800 range. According to the NRS score, $94.7 \%$ of the patients who were consulted to the NSU were malnourished and 5.3\% of them were well-nourished. Albumin levels were very low in $50.5 \%$, low in $37.9 \%$ and normal in $11.5 \%$. When the prealbumin levels were examined, it was found to be very low in $90.5 \%$. CRP levels of patients were $90 \%$ high or very high. It was found out that $19.8 \%$ of the cases were dead. Demographic data on the clinical and nutritional status of the cases are presented in detail in Table 1.

Data on age, height, weight, BMI, calorie need, NRS score, length of hospital stay, albumin, prealbumin, CRP values are given in Table 2. There was a significant difference between malnourished and well-nourished patients in terms of age, BMI, albumin and mortality $(p<0.05)$. Only $10.8 \%$ of the patients with malnutrition according to the NRS score and $23.8 \%$ of the patients without malnutrition were found to have normal albumin levels. It was determined that $84.3 \%$ of patients with malnutrition had normal weight and overweight. No mortality was observed in patients without malnutrition according to NRS. In patients with malnutrition according to NRS, mortality was found to be $20.9 \%$.
In terms of other variables, there was no significant difference between malnourished and well-nourished groups $(p>0.05)$ (Table 3). Mean values of continuous variables in patients with and without malnutrition according to NRS score are shown in Table 4. The mean age of the patients with malnutrition was significantly higher than those without malnutrition. Albumin levels were lower in patients with malnutrition and CRP levels were higher in patients with malnutrition, and this difference was significant $(p<0.05)$.

It was observed that there was no significant difference between the patients' final status (death, discharge, transfer) in terms of

\begin{tabular}{|c|c|c|c|}
\hline & & $\mathbf{n}$ & $\%$ \\
\hline \multirow{2}{*}{ Gender } & Male & 236 & $52.4 \%$ \\
\hline & Female & 214 & $47.6 \%$ \\
\hline \multirow{5}{*}{ Age (years) } & $20-44$ & 24 & $5.3 \%$ \\
\hline & $45-64$ & 104 & $23.1 \%$ \\
\hline & $65-74$ & 96 & $21.3 \%$ \\
\hline & $75-84$ & 132 & $29.3 \%$ \\
\hline & $85+$ & 94 & $20.9 \%$ \\
\hline \multirow{4}{*}{ Diagnosis } & Others (cardiac, renal failure, etc.) & 130 & $29.0 \%$ \\
\hline & Oncological & 138 & $30.7 \%$ \\
\hline & Cardiovascular & 14 & $3.1 \%$ \\
\hline & Neurological & 167 & $37.2 \%$ \\
\hline \multirow{4}{*}{ BMI } & Underweight & 67 & $15.3 \%$ \\
\hline & Normal & 252 & $57.4 \%$ \\
\hline & Overweight & 89 & $20.3 \%$ \\
\hline & Obese & 31 & $7.1 \%$ \\
\hline \multirow{5}{*}{$\begin{array}{l}\text { Calorie } \\
\text { requirement } \\
\text { (kcal/day) }\end{array}$} & $\leq 1200$ & 34 & $7.6 \%$ \\
\hline & 1201-1500 & 118 & $26.2 \%$ \\
\hline & $1501-1800$ & 219 & $48.7 \%$ \\
\hline & $1801-2100$ & 73 & $16.2 \%$ \\
\hline & $\geq 2101$ & 6 & $1.3 \%$ \\
\hline \multirow{2}{*}{$\begin{array}{l}\text { According to } \\
\text { NRS score }\end{array}$} & No malnutrition & 24 & $5.3 \%$ \\
\hline & Malnutrition & 426 & $94.7 \%$ \\
\hline \multirow{3}{*}{ Albumin (g/dL) } & Very low & 138 & $37.9 \%$ \\
\hline & Low & 184 & $50.5 \%$ \\
\hline & Normal & 42 & $11.5 \%$ \\
\hline \multirow{3}{*}{$\begin{array}{l}\text { Prealbumin } \\
\text { (g/dL) }\end{array}$} & Very low & 153 & $90.5 \%$ \\
\hline & Low & 14 & $8.3 \%$ \\
\hline & Normal & 2 & $1.2 \%$ \\
\hline \multirow{3}{*}{$\mathrm{CRP}(\mathrm{mg} / \mathrm{L})$} & Normal & 36 & $10 \%$ \\
\hline & High & 207 & $56 \%$ \\
\hline & Very high & 125 & $34 \%$ \\
\hline
\end{tabular}


BMI levels ( $p>0.05)$. Regarding diagnosis, there was no significant difference between groups in mean calorie $(p>0.05)$.

When the variables were correlated with the NRS score, there was a statistically significant linear relationship between age, albumin, BMI and calorie $(p<0.05)$. A weak positive correlation was found between NRS score and age, whereas there was a weak negative correlation between albumin, BMI and calorie. The correlation between NRS score and the variables is given in detail in Table 5.

\section{DISCUSSION}

It is important to determine possible nutritional risk/ malnutrition in hospitalized patients and this may affect morbidity and mortality (10). Nutrition has a significant impact on health and functional capacity. While the incidence of malnutrition is about $15 \%$ among healthy elderly people, protein energy malnutrition is a major problem in the elderly who are not healthy (11). This rate is up to $80 \%$ especially in hospitalized elderly patients (12). Malnutrition rates in hospitalized patients vary between $15 \%$ and $60 \%$, depending on the type of hospital, the region of the hospital and the population of the study (13). In our study, consistent with the literature, the mean age of the patients was 71 and $71.5 \%$ were in the 65 years old group.

Patients with malnutrition are known to have higher mortality and morbidity rates, longer hospital stay, and more drug use than patients without malnutrition (14). In our study, there was

\begin{tabular}{|c|c|c|c|c|c|}
\hline & $\mathrm{n}$ & Minimum & Maximum & Mean & SD \\
\hline Age (years) & 450 & 20.00 & 101.00 & 71.73 & 15.16 \\
\hline Height (cm) & 450 & 130 & 190 & 165.24 & 9.20 \\
\hline Weight (kg) & 450 & 25 & 112 & 62.40 & 13.83 \\
\hline BMI & 450 & 12.02 & 44.44 & 22.80 & 4.57 \\
\hline $\begin{array}{l}\text { Calorie } \\
\text { requirement } \\
\text { (kcal/day) }\end{array}$ & 450 & 900 & 2400 & 1632.66 & 244.37 \\
\hline NRS & 450 & 1 & 7 & 4.24 & 1.23 \\
\hline $\begin{array}{l}\text { Length of } \\
\text { hospital stay } \\
\text { (days) }\end{array}$ & 450 & 0.00 & 98.00 & 12.64 & 13.66 \\
\hline Albumin (g/dL) & 364 & 1.10 & 43.90 & 2.88 & 2.24 \\
\hline $\begin{array}{l}\text { Prealbumin } \\
\text { (g/dL) }\end{array}$ & 169 & 1.00 & 34.00 & 11.87 & 5.90 \\
\hline CRP (mg/L) & 368 & 0.20 & 361.00 & 87.00 & 73.51 \\
\hline
\end{tabular}

no mortality in the well-nourished group and the mortality rate in the malnutrition group was very high with $20.9 \%$.

None of the plasma proteins, such as albumin, pre-albumin, transferrin, retinol binding protein used in addition to other parameters, are not fully sensitive or specific alone in the assessment of nutritional status (11). However, albumin, prealbumin and CRP are investigated in many different ways such as the evaluation of nutritional status and determination of the prognosis of oncologic patient (15). Albumin is not practical for the evaluation of acute changes in nutritional status due to its long half life; however, it can give better results as a chronic malnutrition index (16). Transferrin is associated with

Table 3. Distribution and relationship of age, gender, diagnosis, BMI, albumin, CRP, prealbumin and mortality rates of patients with and without malnutrition according to NRS score

\begin{tabular}{|c|c|c|c|c|c|c|}
\hline & & \multicolumn{4}{|c|}{ NRS score } & \multirow{3}{*}{$p$} \\
\hline & & \multicolumn{2}{|c|}{ No malnutrition } & \multicolumn{2}{|c|}{ Malnutrition } & \\
\hline & & $\mathbf{n}$ & $\%$ & $\mathrm{n}$ & $\%$ & \\
\hline \multirow{2}{*}{ Gender } & Male & 11 & $45.8 \%$ & 225 & $52.8 \%$ & 0.505 \\
\hline & Female & 13 & $54.2 \%$ & 201 & $47.2 \%$ & \\
\hline \multirow[t]{5}{*}{ Age (years) } & $20-44$ & 4 & $16.7 \%$ & 20 & $4.7 \%$ & \\
\hline & $45-64$ & 14 & $58.3 \%$ & 90 & $21.1 \%$ & \multirow{4}{*}{$0.001 *$} \\
\hline & $65-74$ & 4 & $16.7 \%$ & 92 & $21.6 \%$ & \\
\hline & $75-84$ & 1 & $4.2 \%$ & 131 & $30.8 \%$ & \\
\hline & $85+$ & 1 & $4.2 \%$ & 93 & $21.8 \%$ & \\
\hline \multirow{4}{*}{ Diagnosis } & Neurological & 5 & $20.8 \%$ & 162 & $38.1 \%$ & \\
\hline & Oncological & 11 & $45.8 \%$ & 127 & $29.9 \%$ & \multirow{3}{*}{0.284} \\
\hline & Cardiovascular & 1 & $4.2 \%$ & 13 & $3.1 \%$ & \\
\hline & Others & 7 & $29.2 \%$ & 123 & $28.9 \%$ & \\
\hline \multirow{4}{*}{ BMI } & Underweight & 2 & $8.3 \%$ & 65 & $15.7 \%$ & \multirow{4}{*}{$0.022^{*}$} \\
\hline & Normal & 9 & $37.5 \%$ & 243 & $58.6 \%$ & \\
\hline & Overweight & 9 & $37.5 \%$ & 80 & $19.3 \%$ & \\
\hline & Obese & 4 & $16.7 \%$ & 27 & $6.5 \%$ & \\
\hline \multirow{3}{*}{$\begin{array}{l}\text { Albumin } \\
\text { (g/dL) }\end{array}$} & Very low & 2 & $9.5 \%$ & 136 & $39.7 \%$ & \multirow{3}{*}{$0.012 *$} \\
\hline & Low & 14 & $66.7 \%$ & 170 & $49.6 \%$ & \\
\hline & Normal & 5 & $23.8 \%$ & 37 & $10.8 \%$ & \\
\hline \multirow{2}{*}{ CRP (mg/L) } & High & 10 & $71.4 \%$ & 197 & $61.9 \%$ & \multirow{2}{*}{0.474} \\
\hline & Very high & 4 & $28.6 \%$ & 121 & $38.1 \%$ & \\
\hline \multirow{3}{*}{$\begin{array}{l}\text { Prealbumin } \\
\text { (g/dL) }\end{array}$} & Very low & 4 & $80.0 \%$ & 149 & $90.9 \%$ & \multirow{3}{*}{0.397} \\
\hline & Low & 1 & $20.0 \%$ & 13 & $7.9 \%$ & \\
\hline & Normal & 0 & $0.0 \%$ & 2 & $1.2 \%$ & \\
\hline \multirow{2}{*}{ Death } & Yes & 0 & $0.0 \%$ & 89 & $20.9 \%$ & \multirow{2}{*}{$0.007^{*}$} \\
\hline & No & 24 & $100.0 \%$ & 337 & $79.1 \%$ & \\
\hline
\end{tabular}


iron status and is expected to decrease in nutritional deficiency by increasing the serum concentration of iron deficiency that may be associated with nutritional disorders. Therefore, the use for nutritional assessment is controversial (16). Similarly, in the presence of inflammation, the prealbumin value decreases and the CRP value increases. Correlation of CRP with malnutrition is a matter of debate (17). Prealbumin is a more sensitive nutrient evaluation marker than albumin due to its short half-life of 2 days (15). Ho et al., (18) suggest that low prealbumin levels are an independent risk factor in cancer patients and are used in terminal cancer patients. In our study, no relation was found between the malnutrition group and prealbumin. More studies are needed to clarify this issue.

In their study, Gibbs et al., (19) showed that the low preoperative albumin value was an important indicator of poor clinical course. As albumin may be low in sepsis and inflammatory conditions, it is insufficient to assess the nutritional status with albumin alone (11). Although it is advocated that there is no relationship with nutrition because of its change with body composition, it is still in use in the presence of inflammation and weight loss. Albumin levels can also be used to determine the presence of cachexia (20). In contrast, different studies have shown the relationship with malnutrition $(17,21)$. In our study, albumin was significantly lower in the malnutrition group.

\begin{tabular}{|c|c|c|c|c|c|}
\hline & \multicolumn{4}{|c|}{ NRS score } & \multirow{3}{*}{ p } \\
\hline & \multicolumn{2}{|c|}{$\begin{array}{l}\text { No } \\
\text { malnutrition }\end{array}$} & \multicolumn{2}{|c|}{ Malnutrition } & \\
\hline & Mean & SD & Mean & SD & \\
\hline Age (year) $* *$ & 58.92 & 12.75 & 72.46 & 14.97 & 0.001 \\
\hline Albumin $(\mathrm{g} / \mathrm{dL}) * * *$ & 3.18 & 0.64 & 2.87 & 2.30 & 0.006 \\
\hline Prealbumin $(\mathrm{g} / \mathrm{dL}) * *$ & 15.80 & 4.66 & 11.75 & 5.91 & 0.131 \\
\hline $\operatorname{CRP}(\mathrm{mg} / \mathrm{L})^{* * *}$ & 60.48 & 69.58 & 88.36 & 73.55 & 0.050 \\
\hline $\mathrm{BMI}^{* *}$ & 25.31 & 5.61 & 22.65 & 4.47 & 0.005 \\
\hline Length of hospital stay*** & 9.04 & 8.22 & 12.85 & 13.88 & 0.242 \\
\hline
\end{tabular}

In the literature, it is stated that the length of hospital stay is longer in malnourished patients $(6,22)$. In our study, it was 12.8 and 9 days in the group with and without malnutrition, respectively. However, the difference was not statistically significant. The insignificance was thought to be due to smaller number of patients without malnutrition.

In our study, the correlation test between NRS score and age, albumin, prealbumin, CRP, BMI, length of hospital stay and calorie revealed a weak positive correlation between NRS score and age, and a weak negative correlation between albumin, BMI and calorie. In other words, NRS score increased with increasing age and NRS scores decreased with increasing BMI, calorie need and albumin levels. However, the numerical value of the score was not statistically significant in the malnutrition group (NRS score 3 and above). In addition, there was no statistically significant relationship between NRS score and prealbumin, CRP and length of hospital stay.

\section{Study Limitations}

The study was done for a certain hospital and cannot be generalized to the whole universe. Patient profiles, hospital conditions and procedures may vary. All of the biochemical parameters of the patients were not assessed and the biochemical parameters were evaluated with the available data. The length of hospital stay was evaluated not as the total length of hospital stay of the patient due to the primary diagnosis but as the period starting from the evaluation of the NSU.

\section{CONCLUSION}

Our study emphasized the importance of absolute review of BMI, albumin and CRP levels in order to evaluate the malnutrition of patients with detected malnutrition by NRS-2002. In addition, in patients with malnutrition according to NRS-2002 score, this score does not change the biochemical values, BMI and length of hospital stay when it is between 3-7 points. We think that it is important to monitor the patients closely by establishing NSUs in hospitals, especially in the neurology and oncology clinics, since the detection of malnutrition and nutritional support affect the clinical course.

Table 5. The correlation analysis between NRS score and the variables

\begin{tabular}{|l|l|l|l|l|l|l|l|l|l|l|}
\hline \multicolumn{2}{|c|}{} & NRS & Age & Albumin & Prealbumin & CRP & BMI & Length of hospitalization & Calorie \\
\hline \multirow{2}{*}{$\begin{array}{l}\text { Spearman's } \\
\text { rho }\end{array}$} & NRS & $\mathrm{r}$ & 1.000 & 0.301 & -0.196 & -0.082 & 0.006 & -0.200 & -0.054 & -0.163 \\
\cline { 2 - 11 } & & $\mathrm{p}$ & 0.000 & 0.000 & 0.000 & 0.290 & 0.908 & 0.000 & 0.255 & 0.001 \\
\cline { 2 - 10 } & $\mathrm{n}$ & 450 & 450 & 364 & 169 & 368 & 450 & 450 & 450 \\
\hline
\end{tabular}




\section{Ethics}

Ethics Committee Approval: This study was approved by the Ethics Committee of Izmir Bozyaka Training and Research Hospital, University of Health Sciences (no: 3, dated: 09.08.2016).

Informed Consent: Retrospective study.

Peer-review: Externally peer-reviewed.

\section{Authorship Contributions}

Surgical and Medical Practices: O.Ü., Concept: Y.E.K., C.I., Design: O.Ü., Y.B., Data Collection or Processing: Y.E.K., Y.B., C.I., Analysis or Interpretation: O.Ü., Y.E.K., P.O., Literature Search: O.Ü., P.O., Writing: 0.Ü., P.O.

Conflict of Interest: No conflict of interest was declared by the authors.

Financial Disclosure: The authors declared that this study received no financial support.

\section{REFERENCES}

1. Pirlich M, Schutz T, Norman K, Gastell S, Lübke HJ, Bischoff SC, et al. The German hospital malnutrition study. Clin Nutr 2006;25:563-72.

2. Westergren A, Lindholm C, Axelsson C. Prevalence of eating difficulties and malnutrition among persons within hospital care and special accommodations. J Nutr Health Aging 2008;12:39-43.

3. Sorensen J, Kondrup J, Prokopowicz J, Schiesser M, Krähenbühl L, Meier R, et al. Euro OOPS: an international, multicentre study to implement nutritional risk screening and evaluate clinical outcome. Clin Nutr 2008;27:340-9.

4. Roller RE, Eglseer D, Eisenberger A, Wirnsberger GH. The Graz Malnutrition Screening (GMS): a new hospital screening tool for malnutrition. Br J Nutr 2016;115:650-7.

5. Zhou JD, Wang M, Wang HK, Chi Q. Comparison of two nutrition assessment tools in surgical elderly inpatients in Northern China. Nutr J 2015;14:68.

6. Berbel MN, De Goes CR, Balbi AL, Ponce D. Nutritional parameters are associated with mortality in acute kidney injury. Clinics (Sao Paulo) 2014;69:476-82.

7. Kondrup J, Allison SP, Elia M, Vellas B, Plauth M; Educational and Clinical Practice Committee, European Society of Parenteral and Enteral Nutrition (ESPEN).ESPEN guidelines for nutrition screening 2002. Clin Nutr 2003;22:415-21.
8. Drescher T1, Singler K, Ulrich A, Koller M, Keller U, Christ-Crain M, et al. Comparison of two malnutrition risk screening methods (MNA and NRS 2002) and their association with markers of protein malnutrition in geriatric hospitalized patients. Eur J Clin Nutr 2010;64:887-93.

9. James WP. WHO recognition of the global obesity epidemic. Int J Obes (Lond) 2008;32(Suppl 7):120-6.

10. Norman K, Pichard C, Lochs H, Pirlich M. Prognostic impact of diseaserelated malnutrition. Clin Nutr 2008;27:5-15.

11. Özer B, Kocakuşak A, Tatar C, Koyuncu A, Benek S, Aydın H, ve ark. Elektif cerrahi operasyon planlanan hastaların Pre-operatif nütrisyonel durumunun değerlendirilmesi ve nütrisyonel destek gereksiniminin belirlenmesi. Med Bull Haseki 2016;54:232-6.

12. Holst M, Yifter-Lindgren E, Surowiak M, Nielsen K, Mowe M, Carlsson M, et al. Nutritional screening and risk factors in elderly hospitalized patients: association to clinical outcome?. Scand J Caring Sci 2013;27:953-61.

13. Bayır H, Yıldız I, Erkuran MK, Koçoğlu H. Yoğun bakım hastalarında malnütrisyon. Abant Medical Journal 2015;4;420-7.

14. Naber TH, Schermer T, de Bree A, Nusteling K, Eggink L, Kruimel JW, et al Prevalence of malnutrition in nonsurgical hospitalized patients and its association with disease complications. Am J Clin Nutr 1997;66:1232-9.

15. Ilhan E, Ureyen O, Gökcelli U. Can Prealbumin, Albumin and CRP levels be used to predict prognosis in patients with Gastric Cancer. J Surg Surgical Res 2016;2:30-4

16. Dellière $S$, Cynober L. Is transthyretin a good marker of nutritional status? Clinical Nutrition 2017;36:364-70

17. Ekinci O, Terzioğlu B, Tekeli SÖ, Yilmaz E, Çașkurlu T. The efficacy of nutritional and inflammatory markers in length of hospital stay and mortality prediction in severely malnourished patients. Nobel Med 2013;9:79-85

18. Ho SY, Guo HR, Chen HH, Peng CJ. Nutritional predictors of survival in terminally ill cancer patients. J Formos Med Assoc 2003;102:544-50.

19. Gibbs J, Cull W, Henderson W, et al. Preoperative serum albumin level as a predictor of operative mortality and morbidity: results from the National VA Surgical Risk Study. Arch Surg 1999;134:36-42.

20. Bouillanne O, Hay P, Liabaud B, Duche C, Cynober L, Aussel C. Evidence that albumin is not a suitable marker of body composition-related nutritional status in elderly patients. Nutrition 2011;27:165-9.

21. Vellas B, Guigoz Y, Baumgartner M, Garry PJ, Lauque S, Albarede JL. Relationships between nutritional markers and the mini-nutritional assessment in 155 older persons. J Am Geriatr Soc 2000;48:1300-9.

22. Van Der Kroft G, Janssen-Heijnen MLG, Van Berlo CLH, Konsten J LM. Evaluation of nutritional status as an independent predictor of postoperative complications and morbidity after gastro-intestinal surgery. Clinical Nutrition ESPEN 2015;10:129-33. 